\title{
Textbook of Dental Anatomy, Physiology and Occlusion
}

\author{
Author: Rashmi GS Phulari \\ Publisher: Jaypee Brothers Medical \\ Publishers (P) Ltd \\ Language: English \\ ISSN: 978-93-5025-940-5 \\ Edition: 1/e \\ Publish Year: 2013 \\ Pages: 369 \\ Price: $£ 42.00$
}

The Textbook of Dental Anatomy, Physiology and Occlusion by Dr. Rashmi GS Phulari is a complete guide to dental anatomy, physiology and occlusion for undergraduate and postgraduate dental students.

The book is divided into nine sections and 24 chapters, as follows:

Section 1, Introduction and Nomenclature, has two chapters which give a detailed description of the tooth morphology, on primary and permanent dentition, and various notation systems.

Section 2, Chronology of Tooth Development, which includes two chapters that present the chronology of tooth development, form and function.

Section 3, Deciduous Dentition, presents in two chapters a detailed description of each primary tooth and the differences between primary and second dentition.

Section 4, Permanent Dentition, its eight chapters present a detailed description of each permanent tooth from all aspects.

Section 5, Class arch and type traits of teeth, divided in four chapters which give the common characteristics, the major differences between the maxillary and mandibular class of teeth.

Section 6, Dento-osseous Structures: Temporomandibular Joint, which includes two chapters on the anatomy, blood supply, lymphatics and innervation of craniofacial complex and Temporomandibular Joint.

Section 7, Occlusion, in one chapter describes

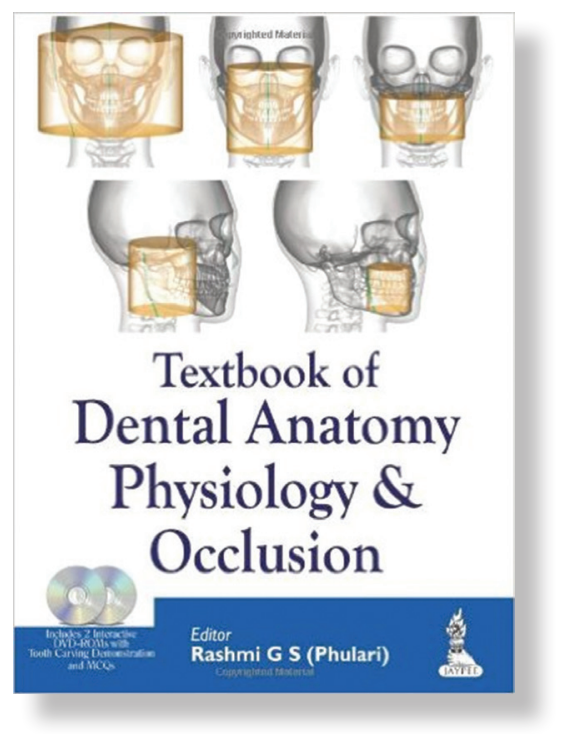

the characteristics of occlusion and malocclusion in primary and second dentition: types of cusps, centric occlusal contacts, tooth guidance, and imaginary occlusal planes and curves.

Section 8, Evolution of Teeth, Comparative Dental Anatomy and Forensic Odontology, has two chapters which give a detailed description of the evolution of teeth, comparative dental anatomy, forensic odontology and dental anthropology.

Section 9, Tooth Carving, in the last chapter explains the rationale, armamentarium, basic principles and step-by-step methodology of the carving procedure.

Each chapter includes multiple choice questions (MCQs) and the additional MCQs in ancillary DVDs to help students prepare for exams, and features numerous high quality photographs and diagrams with descriptions.

The Textbook of Dental Anatomy, Physiology and Occlusion is useful for undergraduate and postgraduate students of dental sciences and dental auxiliaries to teach the concepts of dental anatomy, physiology and occlusion in a simple and logical style.

https://doi.org/10.25241/stomaeduj.2016.3(1-2).bookreview.1

Florin Eugen Constantinescu,DDS, PhD Student

ROPOSTURO-Holistic Dental Medicine Institute, Bucharest, Romania

e-mail:dr.florin.constantinescu@gmail.com

The Book Review is drafted in the reviwer's sole wording and illustrates his opinions. 